\title{
LA REFORMA DE PREDICADORES EN LA REAL CAPILLA DE CARLOS II
}

\author{
POR \\ FRANCISCO JOSÉ GARCíA PÉREZ ${ }^{1}$ \\ Universitat de les Illes Balears-IEHM
}

\section{RESUMEN}

El siguiente artículo persigue el estudio de la reforma de predicadores reales como parte de un programa reformista que afectó a todos los ámbitos de la Real Capilla. A lo largo de estas páginas, se analizarán en profundidad las causas, evolución y consecuencias de la reforma de 1677 , teniendo especialmente en cuenta las circunstancias políticas y económicas que atravesaba la Monarquía Hispánica, concretamente durante el ministerio de Juan José de Austria, y la importancia que había asumido la oratoria sagrada, así como el papel que los predicadores reales jugaron en las distintas facciones de Palacio.

PALABRAS CLAVE: predicadores; Real Capilla; Carlos II; reforma; Juan José de Austria.

\section{THE REFORM OF PREACHERS IN THE ROYAL CHAPEL OF CHARLES II}

\begin{abstract}
The following article pursues the study of the reform of Royal preachers as part of a reform program that affected all areas of the Royal Chapel. Throughout these pages, the causes, evolution and consequences of the reform of 1677 will be analysed in depth, especially considering the political and economic circumstances that crossed the Hispanic Monarchy, specifically during the ministry of Juan José de Austria, and the importance that had assumed the Sacred oratory and the role that the royal preachers played in the different factions of the Palace.
\end{abstract}

KEY WORDS: preachers; Royal Chapel; Charles II; reform; Juan José de Austria.

Cómo CITAR eSte ARtículo / CitATION: García Pérez, Francisco José. 2019. «La reforma de predicadores en la Real Capilla de Carlos II». Hispania Sacra 71, 144: 563-575. https://doi.org/10.3989/hs.2019.040

$\begin{array}{ll}\text { Recibido/Received } & \text { 01-09-2017 } \\ \text { Aceptado/Accepted } & \text { 03-04-2018 }\end{array}$

El estudio de los predicadores reales, y más concretamente la evolución de la Real Capilla de los Austrias durante el siglo XVII, vivió días florecientes hace algunos años. ${ }^{2} \mathrm{El}$ creciente interés por la Corte y todos sus ámbitos se tradujo en trabajos que venían a poner énfasis en la importancia

1 garcia.franj@hotmail.com /

ORCID iD: https://orcid.org/0000-0002-9459-3550

Las abreviaturas utilizadas en este artículo son las siguientes: AGP (Archivo General de Palacio), AHN (Archivo Histórico Nacional), ASV (Archivo Secreto Vaticano), ARSI (Archivum Romanum Societatis lesu), BNE (Biblioteca Nacional de España).

2 Sobre algunos de los trabajos que se centran en la oratoria sagrada y los predicadores reales dentro de la Real Capilla durante el reinado de Carlos II, véase Cerdán 1983, 2000; Álvarez-Ossorio Alvariño 2002, 2004; Sánchez Belén 2014; Azanza López 2013; García Pérez 2015 2017, 2019; Gentili 2012 que la Real Capilla jugó en el Alcázar de Madrid. Si tenemos presente que se trataba de uno de los espacios neurálgicos de la vida palatina, podremos suponer fácilmente que era también allí donde mejor se testimoniaba la misma esencia de la vida cortesana. En lo que al reinado de Carlos II se refiere, actualmente contamos con algunas aportaciones relevantes. Partiendo de los trabajos del profesor Negredo del Cerro sobre los predicadores de Felipe IV, la mayoría de los estudios centrados en este período ya han hecho algunas referencias a la reforma que sufrió la Real Capilla en tiempos de Carlos II, y más concretamente, durante el ministerio de su hermanastro Juan José de Austria. ${ }^{3}$ Dichas referencias se centran en el recorte presupuestario que supuso tal medida,

3 La obra de referencia para conocer la temática de los predicadores reales durante el siglo XVII sigue siendo Negredo del Cerro 2006. 
en coherencia con el programa reformista puesto en marcha por el príncipe. Sin embargo, todavía queda pendiente un estudio en profundidad sobre el impacto que dicha reforma supuso para los predicadores reales. De hecho, la reforma de 1677 se tradujo en la expulsión indiscriminada de un gran número de predicadores reales y el reordenamiento de las normas de acceso a la Real Capilla.

Aunque algunos historiadores han insistido en que primaron unas motivaciones económicas que perseguían la reducción del desorbitado gasto de la Real Capilla, ${ }^{4}$ todo indica que hubo también intereses políticos que no siempre han sido tenidos en demasiada consideración. Con todo lo anterior presente, este artículo propone el estudio de un ámbito específico de la reforma de la Real Capilla en 1677, y más concretamente el que afectó a los predicadores de Carlos II. Para tal fin, se analizarán las circunstancias que motivaron la intervención del poder regio sobre esta élite palatina, sin dejar de lado el contexto político y social que caracterizó los años más conflictivos de la regencia de Mariana de Austria y el ministerio del príncipe don Juan. Seguidamente, se presentará un análisis más o menos profundo sobre el impacto que tuvieron dichas medidas, así como sus consecuencias a corto y largo plazo.

\section{LOS PREDICADORES DE LA REAL CAPILLA EN TIEMPOS DE LA REGENCIA}

Cuando Mariana de Austria asumió el gobierno de la Monarquía Hispánica durante la minoría de edad de Carlos II, la Capilla Real contaba con un número de predicadores muy elevado. ${ }^{5}$ La tendencia de nombramientos que había caracterizado los últimos años del reinado de Felipe IV seguía creciendo sin interrupción. De hecho, el puesto de predicador se había convertido en un premio tan codiciado, que las órdenes religiosas pugnaban por introducir a sus miembros en la plantilla de la capilla del Alcázar de Madrid. En las Constituciones establecidas por Felipe IV en 1623 no se especificaba un número máximo de predicadores, al contrario de lo que ocurría con los capellanes de honor. ${ }^{6}$ Lo único que se demandaba era que «todos aquellos que Nos fuéremos servido nombrar, que sean los más eminentes que hubiere». ${ }^{7}$ Cuando se redactaron dichas Constituciones, el número de ingresos era todavía muy limitado, por lo que aquellos que entraban en plantilla lo hacían por lo general con una remuneración asignada. Pero conforme fue avanzando el siglo XVII, se hicieron cada vez más evidentes los privilegios y atributos inherentes al puesto de predicador, convirtiendo dicha plaza en un premio. Era, por tanto, inevitable que aumentase también la competencia por conseguirla. ${ }^{8}$ De modo que, en los últimos cuatro años de Felipe IV en el trono, fueron nombrados unos 40 predicadores,

\footnotetext{
4 Sánchez Belén 2001.

5 García Pérez 2015: 680.

6 Sánchez Belén 2014: 427.

AGP, Real Capilla, caja 72, ex. 1.

8 A lo largo del siglo XVII, hubo predicadores reales que llegaron a gozar de una situación realmente privilegiada y envidiable por sus contactos con la aristocracia y la familia real. Jerónimo de Florencia, predicador jesuita muy cercano al círculo de la reina Margarita de Austria, gozó de privilegios pocas veces reservados a un predicador cortesano. Véase Garau Amengual 2006: 112.
}

cuando en la primera década del reinado solo se concedió el título a $18 .^{9}$

La regencia de Mariana de Austria fue una época en que proliferó la distribución de mercedes. ${ }^{10}$ Si la Real Capilla heredada de Felipe IV contaba con un número elevadísimo de capellanes de honor, ${ }^{11}$ el caso de los predicadores reales no fue ninguna excepción. Las principales órdenes religiosas escribían insistentemente a la regente suplicando la incorporación de miembros, pues, como decía un provincial dominico, «su religión menos que de otra alguna asiste al servicio del Rey Nuestro Señor (Dios le guarde) en el ministerio de predicadores de $\mathrm{S}$. M». ${ }^{12}$ La situación había llegado a tales niveles que, en 1671, la reina había escrito al patriarca de Indias para que no le propusiera más candidatos porque "al presente hay muchos». ${ }^{13}$ Por aquel entonces, las dificultades financieras de la Corona, la guerra con Francia, el exceso de predicadores en plantilla y los siempre pendientes intentos de limitar el gasto del servicio de Palacio obligaron a que la mayoría de nombramientos se hiciesen ad honorem y sin gajes. ${ }^{14}$ Pero eso no había supuesto ningún problema para que el patriarca de Indias continuase procurando nuevos predicadores a la Real Capilla.

Si en 1667 se había conseguido limitar el número de nombramientos a 7 predicadores, la caída del padre Nithard, y sobre todo la inquietante sombra del bastardo Juan José de Austria amenazando la regencia, motivaron nuevamente la distribución indiscriminada de mercedes, hasta el punto de que entraron 16 nuevos predicadores al año siguiente..$^{15}$ De hecho, cuando murió fray Juan de la Torre, el provincial de San Agustín suplicaba la incorporación de nada menos que tres de sus miembros. ${ }^{16}$ Asimismo, el patriarca de Indias se justificaba en que, "aunque el número de predicadores de V.M. es algo crecido [...], me ha parecido proponer a V.M. tres sujetos de la Compañía [de Jesús] que son los de más crédito en el púlpito». ${ }^{17}$

FIGURA 1

Número de predicadores reales nombrados (1666-1677)

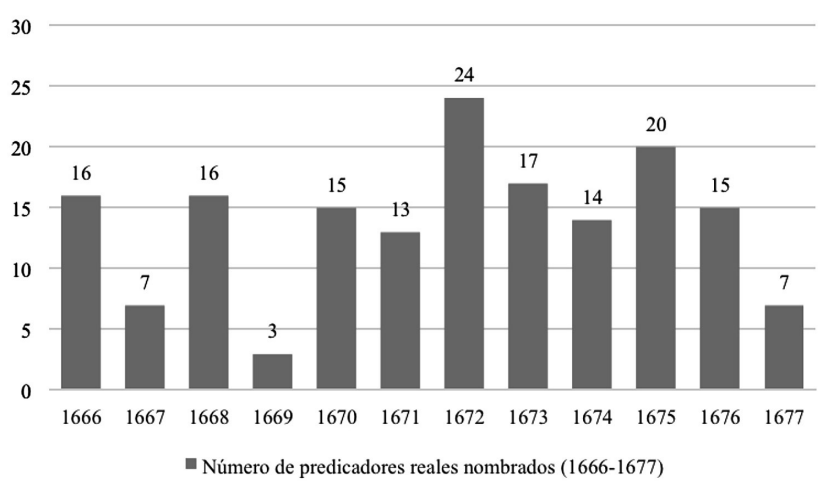

Fuente: AGP, Registro, Libro 6151.

\footnotetext{
9 Negredo del Cerro 2006: 58.

10 Álvarez-Ossorio Alvariño 2004: 108.

11 Hortal Muñoz 2015.

12 AGP, Real Capilla, Caja 218, ex. 2.

13 AGP, Personal, Caja 7736, ex. 9. Expediente de fray Justo Salabert.

14 Sobre la Real Hacienda en tiempos de Carlos II véase el magnífico estudio de Sánchez Belén 1996.

15 AGP, Registro, libro 6151, f. 65 v.

16 AGP, Personal, Caja 7735, ex. 6. Expediente de fray Luis Criado.

17 AGP, Personal, Caja 7734, ex. 7. Expediente de Juan Rodríguez
} Coronel. 
Fue durante la privanza de Fernando de Valenzuela cuando el número de predicadores en plantilla llegó a ser desorbitado. Si durante los cuarenta años del reinado de Felipe IV se designó a un total de 150 predicadores, bajo el periodo de Valenzuela en la Corte hubo 110 nombramientos. ${ }^{18}$ La línea maestra del favorito de la reina se basaba en una «presta distribución de honores y el de un intento de ganar popularidad por todos lados». ${ }^{19}$ Teniendo en cuenta la enrarecida atmósfera que se respiraba en el Real Alcázar de Madrid, con un advenedizo susurrando en el oído de la regente y el príncipe bastardo conspirando para hacerse definitivamente con el poder, podremos imaginar la importancia que llegaron a tener los predicadores para la Corona. ${ }^{20}$ Por aquel entonces, el púlpito de la Real Capilla se había convertido en un foco de posible subversión hacia el poder regio, y especialmente hacia el valido de la reina. ${ }^{21}$ Por eso mismo, era tan importante vigilar a los oradores de Palacio, que en esencia eran aquellos privilegiados que declamaban los sermones en presencia de la familia real.

La década de 1670 fue una época de enorme tensión política que se dejaba traslucir en la Capilla de Palacio. ${ }^{22} \mathrm{~A}$ lo largo del reinado de Felipe IV se había constatado una progresiva instrumentalización de la oratoria sagrada. El conde duque de Olivares había intentado ya supervisar concienciudamente los nombramientos de predicadores reales. ${ }^{23}$ Esta tendencia del trono por controlar el púlpito regio continuó presente bajo la regencia. Durante aquellos años, los enfrentamientos entre Mariana de Austria y su hijastro estaban truncando la estabilidad del gobierno, ya de por sí relativamente frágil por considerarse que el rey era un niño y la reina madre había recuperado la impopular tradición de los validos. ${ }^{24}$ Como venía ocurriendo, los predicadores reales no se habían mantenido ajenos al juego de facciones. Todo lo contrario, esta élite palaciega participaba peligrosamente en aquel ambiente de conspiraciones, adhiriéndose al bando de la regente o apoyando en secreto al bastardo don Juan. ${ }^{25}$ Y era en el púlpito regio donde más visiblemente se constataba la instrumentalización política de la oratoria áulica. ${ }^{26}$ Los predicadores regios cargaban sus sermones de referencias - directas o veladas - a los grandes acontecimientos políticos que estaban teniendo lugar.

Por ejemplo, tras un incendio en la Plaza Mayor de Madrid ocurrido en 1672, el jesuita Juan Rodríguez Coronel, considerado uno de los grandes predicadores de la Corte de Carlos II, exaltaba en un sermón todas las virtudes de la reina frente a las críticas que aumentaban día a día sobre ella: "La Reina nuestra Señora es madre, y solo se llama Reina porque sus piedades cariñosas deslumbran los títulos de la Majestad. [...] Madre religiosamente católica con los que perecieron en la fatalidad del incendio». ${ }^{27} \mathrm{Al}$ año

\footnotetext{
18 AGP, Registro, libro 6151, ff. 67-74.

19 Kamen 1981: 534.

20 Sobre el ascenso político de Fernando de Valenzuela véase Álvarez-Ossorio Alvariño 2015.

21 Álvarez-Ossorio Alvariño 2004: 103.

22 García Pérez 2017: 246

23 Negredo del Cerro 2012: 114.

24 López-Cordón 1998: 60 y ss.

25 Gómez-Centurión Jiménez 1983: 13.

26 Sobre la función política de la oratoria sagrada véase Martínez

27 Rodríguez Coronel 1675: 9.
} Gil 2011. siguiente, predicando el día de Navidad, recordaba a todos que la única persona que podía limitar a un rey era su propia madre. Esto se debía al hecho de que solamente una madre, insistía el jesuita, podía amar tanto a un hijo como para salvarle de sí mismo: «Pues es cordero tierno [Cristo] siga a su madre, y pues es ave deje burladas las esperanzas, huyendo de los que quieren aprisionarle. Las fajas con que le aprisionare su madre serán para fortalecerle los brazos, y para que tenga después más libres y más generosas las manos». ${ }^{28}$ De hecho, durante el período de la regencia, los miembros de la Compañía de Jesús habían sellado lazos muy estrechos con doña Mariana, encumbrando su figura no solo en los púlpitos de los principales templos de Madrid, sino en los de toda España. ${ }^{29}$ La reina se había apoyado en los jesuitas desde su infancia - dejando al margen la importancia que tuvo en su vida su padre confesor - y había respaldado muchos de sus proyectos. ${ }^{30}$ Además, los hijos de la Compañía solían ser sus predicadores favoritos.

Pero los panegíricos a doña Mariana no solo venían de parte de los jesuitas. Numerosos predicadores de otras órdenes querían también exaltar a su patrona. Es el caso del fraile mínimo Juan Ludeña, un anciano predicador de tiempos de Felipe IV, que predicó en 1675 y dedicó su exaltado sermón a la regente. Tratando sobre las dificultades que vivió la Virgen, Ludeña comparaba los pesares de la reina y el acoso permanente de Juan José de Austria con la persecución del rey Herodes sobre María y Cristo: «Ve María Santísima desnuda la espada cruel del inhumano Herodes, amenazando la vida de Cristo Niño [...]. Luego su dolor fue exquisito, porque el corazón suyo y el del Hijo eran uno mismo». ${ }^{31} \mathrm{Y}$ como se acercaba la inminente mayoría de edad de Carlos II, no estaba de más recordar el papel que María ocupaba sentada en los cielos siempre al lado de su hijo: "Cuando [Cristo] comienza a reinar, está tan cuidadoso de su Madre, que ni una palabra menos decente permite que salga de los más airados y desatentos labios. Esta doctrina dio el Señor desde el Trono de su Cruz, cerca del cual asistía su Madre». ${ }^{32}$

Toda aquella campaña de panegíricos no fue suficiente como para ocultar las negativas opiniones que muchos mostraban hacia la reina y su valido, y que empezaban a crecer en la Real Capilla. De hecho, un pequeño grupo de predicadores estaba respondiendo desde el púlpito regio al meteórico ascenso de Fernando de Valenzuela en la Corte. Hacia 1676 eran ya muchos los que apoyaban la causa de Juan José de Austria. ${ }^{33}$ Mientras algunos predicadores se habían posicionado del lado de la regente -y por lo tanto también del lado del favorito-, otros tantos ansiaban la entrada del príncipe en Madrid. ${ }^{34}$ Si por aquel entonces hubo un defensor acérrimo de Juan José de Austria, ese fue el trinitario fray Manuel de Guerra y Ribera, cuyos sermones

\footnotetext{
28 Rodríguez Coronel 1695: 221.

29 Burrieza Sánchez 2008: 202.

30 Lozano Navarro 2005: 337.

31 Ludeña 1675: 11.

32 Ludeña 1675: 20.

33 Durante los diez años de regencia, fueron muchos, tanto dentro como fuera del Real Alcázar, los que defendieron la trayectoria política de Juan José de Austria, considerándolo el más apto para asumir el valimiento en contraposición a las opciones de la regente, es decir, Nithard y Valenzuela. Hermosa Espeso 2014: 113.

34 Álvarez-Ossorio Alvariño 2004: 100.
} 
ensalzaban todas sus virtudes..$^{35}$ Valiéndose de su carisma y la fama que había cosechado en la Real Capilla, el padre Guerra se atrevió en un sermón predicado el año de 1675 a recomendar a la reina que se aviniese a pactar con su hijastro, por el bien de la Monarquía y del joven rey. ${ }^{36}$ Al año siguiente, predicando el día de santa Ana en presencia de la familia real, censuraba a aquellos ministros que acumulaban en sus manos altos niveles de responsabilidad política, aun cuando se veían incapaces de asumir tan pesada carga. Estas referencias pretendían criticar, obviamente, el meteórico ascenso al poder de Fernando de Valenzuela: «Formar al fuego es hechura de priesa: fabricar al torno es hechura con pereza. Y fábrica de respeto tan alto como la mano de un Príncipe, no se debe formar a las celeridades de una priesa, sino a las pausas de una experiencia». ${ }^{37}$ Parece ser que, tras predicar aquellos atrevidos sermones, fue desterrado a distintas ciudades de la península y es posible que permaneciese recluido en prisión. ${ }^{38}$

No fue extraño, por tanto, que Fernando de Valenzuela iniciase una purga de predicadores en Palacio por sus supuestos contactos con el hijo bastardo de Felipe IV. ${ }^{39}$ De hecho, en 1676, el favorito de la reina les estaba vigilando de cerca, hasta el punto de que - se decía irónicamente«eran precisamente registrados los sermones en papel antes que se publicasen en el púlpito". ${ }^{40}$ La sagacidad de Valenzuela para convertirse en los oídos de la Corona le valió también para descubrir algunos predicadores sediciosos. Entre estos, el dominico fray Antonio Vergara estaba siendo constantemente vigilado por los espías del Duende. Al parecer, se rumoreaba que se había reunido en su celda con afectos a la causa de don Juan. Pero, además, en el púlpito «se había adelantado en los sermones a más de lo que tocaba en su Ministerio de Predicador $"{ }^{41}$ por lo que finalmente fue expulsado de la Corte. Destino similar sufrieron otros predicadores como el jerónimo fray Francisco Rubio, que se había excedido en su predicación, haciendo continuas referencias a la causa de don Juan en el púlpito, que disfrazaba infructuosamente con citas bíblicas. ${ }^{42}$ Por orden regia, se le prohibió volver a predicar en Palacio hasta nuevo aviso.

La situación llegó hasta tal punto que los Grandes se rebelaron ante la presencia del marqués de Villasierra, creyendo «prostituida la Grandeza cuando este favorito fue admitido en ella, dándole asiento en el banco de la Capilla Real». ${ }^{43} \mathrm{En}$ la primavera de 1676 los ánimos dentro del Alcázar se hallaban más exaltados que nunca. Aunque Carlos II había sido declarado mayor de edad desde noviembre del año anterior, la reina y Valenzuela continuaban manteniendo el control del gobierno, como hasta entonces había sido. Y en la Real Capilla la purga de predicadores desafectos había continuado su curso, mientras nuevos aspirantes ingresaban sus filas, llegando a ser incorporados 15 predicadores más en ese año. ${ }^{44}$ Asimismo, los fieles a la reina madre seguían

\footnotetext{
35 García Pérez 2017: 246.

36 Guerra y Ribera 1677: 36

37 Guerra y Ribera 1677: 9.

38 Soria Ortega 1991: 62.

39 Maura 1990: 177.

40 CODOIN, Tomo 67, Madrid, 1877, 28.

41 AHN, Estado, Libro 880, f. 181.

42 Álvarez-Ossorio Alvariño 2004: 109.

43 BNE, ms. 18211, f. 5.

44 AGP, Registro, Libro 6151, f. 74.
}

defendiéndola frente a los ataques cada vez más feroces y las sátiras políticas que inundaban las calles de Madrid. En la Cuaresma de ese mismo año, el afamado jesuita Rodríguez Coronel sermoneó en la Real Capilla a los asistentes sobre «que es verdad que es acto más heroico de valor el perdonar el agravio que el vengarle. [...] Respondo negando que pueda nacer de pechos que se precian de cristianos y de católicos juicio tan errado». ${ }^{45}$ Quizás hablaba sobre los reiterados intentos de Juan José de Austria por vengarse de los desplantes sufridos por su madrastra.

En diciembre de 1676 se desmoronó el gobierno de Valenzuela en Palacio. Primeramente, los Grandes firmaron un memorial en el que se resistían a la presencia del favorito de la reina por más tiempo en la Corte y apoyaban las demandas del príncipe. ${ }^{46}$ A continuación, Carlos II, motivado por las voces que le aconsejaban llamar a su hermano a su lado, dio permiso al marqués de Villasierra para abandonar el Alcázar, ordenando a los jerónimos del monasterio de El Escorial que "lo recibáis en él y le aposentéis en los aposentos de Palacio que se le señalaron cuando yo estuve en ese $2 .{ }^{47}$ Poco duraron los privilegios de Valenzuela, porque a inicios de ese mismo año Juan José de Austria entraba triunfante en Madrid con un ejército y se ocupaba de apartar al rey de su madre, que quedó relegada en Toledo. ${ }^{48}$ A continuación, asumió el cargo de primer ministro de la Monarquía e inició una batería de reformas para acabar con la inestabilidad política, sanear la economía y reforzar el papel de la Corona. ${ }^{49} \mathrm{Y}$, como era de esperar, entre esas reformas hubo planes también para la Real Capilla.

\section{2. «EL NÚMERO DE TRES»: LA REFORMA DE PREDICADORES EN 1677}

A lo largo del siglo XVII hubo ya intentos de reforma dentro de la Real Capilla, la mayoría de ellos destinados a sanear las arcas de la Real Hacienda. ${ }^{50}$ En 1634 el patriarca de Indias había propuesto a Felipe IV distintas medidas que ayudasen a este objetivo, aunque él mismo se mostraba escéptico con los posibles resultados, pues «el fin de V.M. es excusar gastos en el tiempo presente, pero no es de creer del Real ánimo, intención y piedad de V.M. que esto sea con detrimento de los que están actualmente sirviendo». ${ }^{51}$ Si hubo alguna oportunidad de cambio, se vio definitivamente truncada durante el período de la regencia. Mariana de Austria reforzó el desbordante cupo de nombramientos que se producían año tras año, pese a que ordenó al patriarca que «no me consultéis nuevamente a ninguno de los que sirven en la Capilla en aumentos ni gajes». ${ }^{52} \mathrm{Y}$ aunque es cierto que la mayoría de nombramientos se hizo a título honorífico, los compromisos del privado Fernando de Valenzuela y el crecimiento imparable de incorporaciones estaban haciendo insostenible la situación.

45 Rodríguez Coronel 1694: 347

46 BNE, ms. 2034, f. 181.

47 AGP, Personal, Caja 1060, ex. 9. Expediente de Fernando de Valenzuela.

48 BNE, ms. 18443, f. 232.

49 Véase Castilla Soto 1990.

50 Negredo del Cerro 2006: 58.

51 AGP, Real Capilla, Caja 218, ex. 2.

52 AGP, Real Capilla, Caja 70, ex. 1. 
A esto había que sumarle la implicación que los predicadores reales tenían ya en las facciones de la Corte. Si durante el reinado de Felipe IV distintos personajes habían utilizado su oratoria para lanzar sermones cargados de críticas o exaltación hacia el rey o su valido, bajo la regencia la instrumentalización del púlpito era ya un hecho consumado. ${ }^{53}$ Aunque algunos predicadores jamás se atrevieron a entrar en aquel peligroso juego, muchos otros estaban yendo demasiado lejos. Los jesuitas habían lanzado todas sus armas para desprestigiar a Juan José de Austria, elogiando a la reina madre y comparando al bastardo con los personajes más aborrecibles de la Biblia. ${ }^{54}$ Mientras tanto, predicadores como Guerra y Ribera o Francisco Rubio exaltaban al príncipe como si de un salvador de la Monarquía se tratase. ${ }^{55} \mathrm{Y}$, al mismo tiempo, otros tantos estaban siendo purgados de la Real Capilla y expulsados de Palacio por sus peligrosos compromisos. Todo esto justifica el que, una vez Juan José de Austria se hizo con el control del gobierno en 1677 , iniciase reformas inmediatas sobre la capilla palatina del Alcázar de Madrid.

El 20 de febrero de ese año, Carlos II - siempre supervisado por su hermanastro- ordenó al patriarca de Indias que "se tenga una Junta en que han de concurrir el condestable de Castilla, mi mayordomo mayor, y otros quien he nombrado, y porque también habéis de asistir en ella vos». ${ }^{56}$ La idea era conformar una Junta que supervisase las reformas destinadas a reducir los gastos que afectaban a la Casa Real, que incluía también a la Real Capilla. ${ }^{57} \mathrm{Y}$ aunque a priori parecía otro intento más que iba a terminar frustrado, Juan José de Austria se ocupó personalmente de que dichas reformas se convirtiesen en una realidad. Visto por muchos como el restaurador de una gloria ya perdida, el nuevo primer ministro no cejó en su empeño por reforzar el poder regio y acabar con cualquier referencia al período de la regencia y los años de Mariana de Austria como guardiana del trono. ${ }^{58}$ De modo que, lo primero que hizo, fue asumir la política de persecución y destierros que ya había puesto en marcha Fernando de Valenzuela. ${ }^{59}$ De hecho, para implantar las necesarias reformas, Juan José de Austria necesitaba a hombres de confianza en los máximos organismos de poder. A todo esto se le sumaban, claro está, sus motivos personales para orquestar la venganza contra todos los que le habían despreciado. ${ }^{60}$

El mismo privado de la reina, que se había refugiado en El Escorial, fue el primero en caer en las manos del príncipe. Aunque estaba acogido a sagrado, "fueron los duques y muchos soldados, [...] y se encaminaron derechos al

53 Véase Cerdán 1983: 224.

54 García Pérez 2019: 104.

55 Herrero Salgado 2006.

56 AGP, Real Capilla, Caja 218, ex. 2.

57 Sánchez Belén 2001: 377.

5 Lynch 1992: 329.

59 Carrasco Martínez 1999: 103.

60 El duque de Maura ya hablaba de la persecución que puso en marcha don Juan una vez se hizo con el poder en palacio: «Extremó hasta la crueldad la persecución, no solo contra las criaturas del Duende, sino contra deudos y amigos de los Valenzuela que continuaron siéndoles fieles en el infortunio. [...] Vengó, claro es, todos sus agravios políticos recientes; pero mostró su poco generosa inclinación saciando además antiguos rencores, no recordados ya sino por su implacable amor propio». Maura 1990: 207. puesto y le sacaron y prendieron». ${ }^{61} \mathrm{~A}$ continuación, don Juan se ocupó de limpiar el Alcázar de los aliados y fieles a Valenzuela. ${ }^{62}$ Sus enemigos no tardaron en murmurar por los rincones de Palacio que "se ocupaba más en las distinciones de su carácter y empleo, que en buscar la felicidad de los pueblos». ${ }^{63} \mathrm{Si}$ bien algunos historiadores han considerado que su política de venganza fue limitada, y que no se ajustaba a las elevadas críticas que recibió durante y después de su gobierno, ${ }^{64}$ debe tenerse presente que la sombra del príncipe bastardo alcanzó indirectamente a muchos criados de Palacio. De hecho, en la Real Capilla se planificó una drástica reforma, presentada como una medida necesaria para reducir el desorbitado gasto, que significó la expulsión indiscriminada de muchísimos predicadores reales.

Dicha reforma afectó a todos los ámbitos de la capilla palatina: desde el ceremonial litúrgico y el boato religioso, hasta los criados que componían su personal. En lo que se refiere a la plantilla de predicadores reales, se pretendía limitar radicalmente su número. ${ }^{65}$ De modo que, el 24 de marzo de 1677, Carlos II ordenó al patriarca que «me propongáis luego los sujetos que juzgaréis por más dignos, para quedar en este ejercicio en el número y conformidad referidas para que yo tome resolución». ${ }^{66}$ La idea era que cada religión mantuviera únicamente a tres miembros, y que se realizasen nuevos nombramientos conforme quedaran plazas vacantes. ${ }^{67}$ Esta medida solo concernía a los predicadores nombrados tras la muerte de Felipe IV, de modo que todos aquellos incorporados antes de 1665 estaban exentos del número de tres. No es difícil observar que esta condición afectaba a los predicadores admitidos durante el período de la regencia, es decir, todos los que habían sido designados por la reina Mariana de Austria. Aquí se deduce que la medida no tenía únicamente fines económicos. Aunque es cierto que se pretendía reducir el gasto del personal de la Real Capilla, se estaba expulsando de Palacio a un sinnúmero de predicadores que debían su título a la reina madre.

El patriarca de Indias no pareció estar demasiado conforme con el plan de reforma, pues «no parece de la grandeza de V.M. ni de su benignidad revocar las mercedes hechas y echar absolutamente de su Real Casa a los que una vez dio entrada en ella con el título de criados». ${ }^{68} \mathrm{Sin}$ embargo, no tuvo más remedio que elaborar la lista de aquellos predicadores que debían continuar en plantilla, lo cual no fue nada sencillo por diversos motivos. Primeramente, don Antonio Manrique de Zúñiga y Guzmán sabía que debía salvar de la expulsión a todos los predicadores que habían arriesgado su vida por el príncipe. Estuviese de acuerdo o no con su permanencia, no tenía opción alguna. De modo que fray Manuel Guerra y Ribera y el jerónimo Francisco Rubio retornaron a la Corte y continuaron en su puesto como así se esperaba. Además, el dominico fray Antonio de

61 AGP, Personal, Caja 1060, ex. 9. Expediente de Fernando de Valenzuela.

62 Sobre las políticas de destierro que implantó Juan José de Austria en los distintos Consejos de la Monarquía mientras fue primer ministro véase Kalnein 2001: 425.

63 BNE, ms. 18211, f. 7.

64 Kamen 1981: 540.

65 Álvarez-Ossorio Alvariño 2002: 315.

66 AGP, Real Capilla, Caja 218, ex. 2.

67 Álvarez-Ossorio Alvariño 2004: 103.

68 AGP, Real Capilla, Caja 70, ex. 1. 
Vergara, que había sido desterrado durante el ministerio de Valenzuela por sus contactos con los aliados del príncipe, también estuvo en la lista, pese a que había sido enviado a las Indias tras su expulsión de Palacio. ${ }^{69}$

Otro problema era que muchos predicadores provenían de algunas de las estirpes nobiliarias más poderosas de Castilla. El desplante que suponía para las grandes familias de la aristocracia el ver expulsados a sus hijos o sobrinos, era algo que no debía tomarse a la ligera. De hecho, el patriarca advirtió al rey sobre la necesidad de buscar algún puesto alternativo para estos sujetos, "siendo de tanta recomendación por su sangre y por los puestos de letras y superioridad que tienen en sus religiones $" .{ }^{70} \mathrm{Y}$, finalmente, estaba el contratiempo de que algunos capellanes de honor habían conseguido ser nombrados predicadores reales tras años de servicio. Esto sirvió al patriarca de Indias para suplicar que se conservase a estos sujetos únicamente por su plaza de capellanes, lo cual reducía el número de expulsiones. El Dr. Pedro Rodríguez Monforte, que además de capellán de honor se había convertido en una de las voces más demandadas del púlpito regio, se salvó de ser despedido por su doble condición. ${ }^{71}$

Las principales religiones continuaron representadas por tres miembros, pero hubo excepciones que confirmaron las motivaciones políticas que ocultaba dicha reforma. Dentro de aquella lista el patriarca mantuvo también a tres predicadores de la Compañía de Jesús, en concreto tres jesuitas que él mismo había propuesto a la regente en 1672: Juan Ignacio de Castro Verde, Tomás Sánchez y Juan Rodríguez Coronel. ${ }^{72}$ Precisamente este tercero era considerado uno de los panegiristas más activos de la reina Mariana, además de predicador de gran relevancia. ${ }^{73}$ Ya durante la primera Cuaresma del príncipe en Madrid tras su asalto al poder, el jesuita había lanzado algunas críticas hacia el gobierno, valiéndose de la figura de un príncipe llamado Absalón que se había rebelado contra su padre, el rey David, para hacerse con el trono. Pues bien, don Juan no permitió que estos jesuitas continuasen en plantilla. Considerados por aquel entonces "grandísimos sujetos del Colegio Imperial, [...] se les castigó la sospecha con escandaloso destierro de la Corte». ${ }^{74}$ Destino similar sufrió Manuel de Nájera, predicador de tiempos de Felipe IV. Aunque estaba exento del número de tres porque su nombramiento se había producido antes de 1665, eso no le valió la misericordia del primer ministro, siendo expulsado del Real Alcázar. ${ }^{75}$

Ahora que la reina madre estaba recluida en Toledo, su mano protectora había desaparecido drásticamente $y$, tras décadas de gran ascendencia en la Corte de los Austrias, las relaciones entre la Compañía y la Corona se vieron reducidas al mínimo. ${ }^{76}$ Con el tiempo, y conforme la influencia y el poder don Juan fueron menguando, se permitiría a

69 AGP, Personal, Caja 7730, ex. 7. Expediente de fray Antonio de Vergara.

70 AGP, Real Capilla, Caja 218, ex. 2.

71 AGP, Personal, Caja 7804, ex. 4. Expediente de Pedro Rodríguez de Monforte.

72 AGP, Personal, Caja 7734, ex. 7. Expediente de Juan Rodríguez Coronel.

73 García Pérez 2019: 127.

74 BNE, ms. 6641, f. 64.

75 Álvarez-Ossorio Alvariño 2004: 104.

76 Lozano Navarro 2005: 345. estos tres predicadores retornar a Palacio. Esto lo sabemos porque se han conservado algunos sermones que Rodríguez Coronel y Tomás Sánchez predicaron en 1678 ante el rey, además de que los tres volvieron a residir en el Colegio Imperial de Madrid. ${ }^{77}$ Sin embargo, el discurso de estos predicadores estuvo siempre vigilado y sujeto a las exigencias del príncipe.

Una vez redactada la lista, se procedió a informar a todos los que no habían tenido la suerte de mantenerse en ella. De pronto, generaciones de predicadores que habían batallado sin descanso para obtener una merced más que codiciada, recibían la noticia de su expulsión de la plantilla de predicadores. Obviamente hubo algunas excepciones reseñables. El patriarca de Indias se había visto obligado a sacar de la lista a su propio hermano, el franciscano fray Alonso de Guzmán, principalmente por ser una de las incorporaciones más recientes. Sin embargo, pasados unos meses, suplicó al rey que se le permitiese volver a Palacio. Y, como cabía esperar, Carlos II le contestó que "sin embargo de lo que tengo resuelto sobre el número que han de quedar los predicadores de mi Real Capilla, he venido en que corra el título que estaba despachado para este ejercicio a fray Alonso de Guzmán, vuestro hermano». ${ }^{78}$

El siguiente paso fue adaptar la etiqueta cortesana a la privilegiada situación de Juan José de Austria como primer ministro. La vida en la Corte estaba totalmente reglamentada y se sustentaba en una veterana tradición. De hecho, cuando Fernando de Valenzuela fue elevado a la grandeza, los Grandes de España dejaron de ocupar su banco reservado en la Real Capilla por el insulto que suponía compartirlo con un advenedizo. ${ }^{79}$ Tras el ascenso al poder de don Juan, debía precisarse con exactitud cuál iba a ser su lugar y posición en los rituales que tenían lugar en la Capilla de los Austrias. ${ }^{80}$ El nuevo primer ministro quería estar lo más cerca posible de su hermanastro, adquiriendo así una situación privilegiada, en esencia lo que había ambicionado desde su juventud. El nuncio papal Savo Millini creía ver en todo aquello una estrategia oculta para «esser dichiarato Infante potendoli ciò riuscire per la libera volontà de il Re che tiene a sua disposizione e per il timore che hanno i Grandi di lui». ${ }^{81}$ De modo que, a instancias de su hermano, Carlos II ordenó que «en el acompañamiento desde que salgo de mi cuarto para pasar por el corredor a la capilla, y en las demás funciones de esta planta, vaya don Juan un paso delante de mí con preferencia a los Grandes y a los jefes de mi Casa». ${ }^{82}$ A continuación, quedó establecido que don Juan tendría también una silla inmediata a la del rey en la capilla, quedando muy por encima de los Grandes de España. ${ }^{83}$

Para justificar todas estas novedades, el Consejo de Estado buscó precedentes en el pasado. Concretamente, se retrotrajeron a otro Juan de Austria, hijo natural del emperador Carlos V. Aquel príncipe bastardo también había gozado de una situación muy cercana a la familia real,

\footnotetext{
77 ARSI, Toletana, Catalogi Breves, 15, 1623-1678, f. 352.

78 AGP, Personal, Caja 7737, ex. 3. Expediente de fray Alonso de

79 Álvarez-Ossorio Alvariño 2004: 100

80 Kalnein 2001: 487.

81 ASV, Segreteria di Stato, Spagna, 148, f. 185.

82 AGP, Libro de Registro 6151, f. 160.

83 Álvarez-Ossorio Alvariño 2002: 321
} Guzmán. 
especialmente con su hermanastro Felipe II. De hecho, tuvo una presencia muy activa en las grandes ceremonias religiosas que se orquestaban en la Capilla Real. Por ello, los miembros del Consejo recogieron distintas ocasiones que justificaban, en cierta manera, la nueva situación del hermano de Carlos II: «El año de 1560, en 22 de febrero, se celebró en Toledo la jura del príncipe don Carlos, hijo del Sr. Rey Don Felipe el 2으, y en el acompañamiento llevó el Sr. Don Juan de Austria la mano izquierda del Príncipe». ${ }^{84}$

De un modo u otro, la sombra de don Juan se extendió por todos los rincones del Alcázar de Madrid, y muy pronto se supo que, quien deseara medrar en aquella Corte, debía contar con el favor del príncipe. Una prueba de ello fueron los exaltados sermones que poblaron la Real Capilla entre 1677 y 1679. Los predicadores que se salvaron de ser expulsados sabían que su estrella continuaría brillando mientras jugasen según las reglas que dictaba el hermanastro del rey. Los ataques y desplantes de épocas pasadas llegaron a su fin. De hecho, «los predicadores, ya en la Capilla, ya en la Corte, esclavos de la adulación, gastaban más en elogios que en las reprensiones ${ }^{85}$ De comparársele con personajes despóticos como el rey Herodes o el príncipe Absalón, don Juan pasó a ser identificado con Moisés o Juan Bautista, que representaban símbolos de la esperanza frente a una tiranía que ahora encarnaba la reina Mariana de Austria, recluida en Toledo.

Fray Manuel Guerra gozó de una situación inmejorable y consolidó su fama como uno de los predicadores favoritos de don Juan. Durante aquellos dos años, el trinitario tuvo oportunidad de predicar muchas veces en la Capilla Real, elogiando la figura del príncipe sin disimulo. ${ }^{86} \mathrm{En}$ 1677 le dedicó un libro de sermones sobre santos, "porque habiendo sido la sombra de V.A. amparo de mi voz, es empeño de su grandeza ser su nombre templo de mi pluma». ${ }^{87}$ Junto a él, otro de sus incondicionales panegiristas, el jerónimo fray Francisco Rubio, continuó con su práctica de dedicar los sermones a aquel que siempre le había protegido. Cuando se celebraron las honras a Felipe IV en la Real Capilla en septiembre de 1677, Rubio agradeció enormemente la presencia de Su Alteza, pues «bien conozco que es atrevimiento, pero disculpable es, pues fue servido S.A. de significar que le pareció bien cuando lo merecía por oyente ${ }^{88}$ Ciertamente, sus apoyos a la causa del príncipe le valieron recompensas importantes, pues, desde hacía algunos años, se le vulneraban sus privilegios de predicador en el convento donde residía «porque como no es profeso en la casa de Madrid (según el estilo de la religión) como huésped no le dan más que una celda sin otra cosa». ${ }^{89}$ Finalmente, se le concedieron cuatrocientos ducados de pensión, aun cuando la asignación de gajes había quedado totalmente interrumpida.

La reforma de la Real Capilla pronto presentó algunos contratiempos. En 1678 la lista de predicadores designados había continuado intacta y el flujo de nombramientos se había detenido. La reforma había significado un duro golpe

84 AHN, Estado, leg. 2783.

85 CODOIN, Tomo 67, Madrid, 1877, pág. 28.

86 García Pérez 2017: 254.

87 Guerra y Ribera 1677: 2.

88 Rubio 1677: 2.

89 AGP, Personal, Caja 7733, ex. 1. Expediente de fray Francisco para órdenes religiosas como las de los franciscanos, dominicos o agustinos, demasiado acostumbradas a planificar la introducción de sus miembros en el ambiente cortesano como un modo de consolidar su influencia en las altas esferas. Como puede imaginarse, los superiores suspendieron el envío de nuevos informes proponiendo candidatos, visto lo improbable de nuevas incorporaciones. Además, ya no era a Carlos II, sino a don Juan a quien debían dirigirse para solicitar el favor regio. Por ejemplo, tras su expulsión de la Capilla, el jerónimo fray Juan de San Francisco escribió directamente al príncipe suplicando «a V.A. sea servido de interceder con S.M. para que dicho fray Juan de San Francisco prosiga en el ejercicio de la plaza de su predicador $" .{ }^{90}$ Su petición no se vio satisfecha. De hecho, en los dos años de ministerio de don Juan, solo se incorporaron nueve predicadores reales y ninguno de los expulsados, a excepción del hermano del patriarca, consiguió regresar. ${ }^{91}$ Una circunstancia que no implicó necesariamente una disminución del gasto, o sea el fin principal de aquella radical reforma que había supuesto la expulsión de palacio de tantos predicadores. Esto lo demuestra el hecho de que, en 1679, Carlos II escribió al patriarca de Indias ordenándole que se abstuviese nuevamente de solicitar aumentos en los gajes de los criados. ${ }^{92}$

Por otro lado, en la Junta que dirigía la evolución de las reformas habían crecido las disputas internas y las tensiones, hasta el punto de que el patriarca se quejó a Carlos II refiriendo que se vulneraban continuamente sus privilegios de capellán mayor. Los enfrentamientos con el condestable de Castilla estaban Ilegando a un punto insostenible para el patriarca, y es «que su capellán mayor se halla tan condecorado, [que] no se dé lugar a semejante introducción, y más cuando no hay costumbre a favor del mayordomo mayor ${ }^{93}$ Al mismo tiempo, la Junta de Obras y Bosques que gestionaba los Reales Sitios, nombró a diferentes capellanes sin contar con la aprobación de don Antonio Manrique, «que es contra el estilo y contra toda razón de Gobierno en que se ha fundado, siendo la más esencial (dejando aparte la autoridad del oficio de capellán mayor y la fuerza que induce el estilo) que el tal capellán ha de administrar los Santos sacramentos". ${ }^{94}$

\section{LA MUERTE DE JUAN JOSÉ DE AUSTRIA y LOS LíMITES DE LA REFORMA DE PREDICADORES}

Tras unos primeros destellos de luz que presagiaban la llegada de nuevos tiempos, Juan José de Austria se hizo consciente de las enormes dificultades que se le venían encima. El primer ministro tenía que lidiar con contratiempos tanto dentro como fuera del Alcázar de Madrid. Primeramente, los Grandes habían empezado a retirarle su apoyo, sobre todo después de las impopulares reformas de recorte del gasto público y el lujo. ${ }^{95} \mathrm{El}$ mismo hecho de que don Juan ocupara en la Real Capilla un sitial tan privilegiado, muy por encima del banco de los Grandes, resultaba para

90 AGP, Personal, Caja 7740, ex. 10. Expediente de fray Juan de San Francisco.

91 AGP, Registro, libro 6151, f. 76 v.

92 Sánchez Belén 2001: 418.

93 AGP, Real Capilla, Caja 218, ex. 2.

94 AGP, Real Capilla, Caja 18, ex. 5.

95 BNE, ms. 2289, f. 203. 
muchos algo intolerable. ${ }^{96}$ Además, en las calles de Madrid la falta de pan se achacaba a aquel príncipe, que de mesías estaba pasando a ser retratado como un simple embaucador. Incluso la paz que se había sellado con Francia era vista en términos verdaderamente negativos. Nimega representaba, de hecho, la mayor vergüenza para don Juan y un símbolo evidente de que su poder empezaba a desvanecerse. Por todo lo anterior, las críticas hacia él fueron ya imparables y ni siquiera los exaltados sermones panegíricos de fray Manuel Guerra pudieron ensombrecerlas.

Aunque don Juan había tejido una red de espías que perseguía la producción y distribución de pasquines satíricos, pronto se demostró que nada podía detener aquellas voces críticas, que ya habían sido una constante durante las décadas anteriores del siglo XVII. ${ }^{97}$ Por las calles se comparaba a Judas, el apóstol traidor y favorito de Cristo, con don Juan, del mismo modo que él era - en apariencia- el favorito del rey: «A Judas Cristo Jesús para Apóstol eligió, todos culpan su codicia, más ninguno su elección ${ }^{98}$ Al mismo tiempo, se acusaba a Juan José de Austria de ser un farsante, que había engañado a todos sus allegados para alcanzar el escalón más elevado del poder: «Este Señor debe el ser hijo del Rey a la mentira; debe el ser gran soldado a la mentira; debe el ser gobernador de España a la mentira; debe el tener la gracia del Rey a la mentira». ${ }^{99}$

Pero si hubo críticos mordaces, esos fueron los jesuitas. La Compañía de Jesús vivía sus días más aciagos, después de décadas arropada por los más poderosos. Aunque predicadores como Rodríguez Coronel o Castroverde se sometieron a aquella opresiva atmósfera en el Real Alcázar con tal de permanecer en el «número de tres», muchos de los que habían sido expulsados no temían ya despertar las iras de don Juan. Apoyando abiertamente a la reina Mariana, dedicaban todas sus fuerzas a acabar con la imagen del príncipe bastardo. Y entre ellos, el padre Juan Cortés Osorio fue uno de los más apasionados detractores, hasta el punto de ser llamado «el Juvenal español». ${ }^{100}$ Criticando abiertamente a don Juan en su Invectiva Política, reflexionaba sobre el hecho de «que el rey Felipe IV siempre temió el estorbo de un bastardo, y que con altísima providencia le excluyó del gobierno ". ${ }^{101}$ Pero el jesuita no se detuvo en él. Además, criticó a los predicadores que tanto apoyo habían brindado al príncipe, en especial el padre Guerra. El trinitario se había identificado tan ardorosamente con su causa, que fue también blanco de los ataques: «Callen señores, replicó el Temor, y adviertan que la Esperanza [don Juan] tiene un fraile de ayuda, y si le suelta los aturdirá a sermones». ${ }^{102}$

Si alguien hizo peligrar realmente el puesto de Juan José de Austria, ese fue el mismísimo rey. Pasado el primer año, Carlos II seguía extrañando a su madre, en esencia la mujer que le había acompañado en cada uno de los momentos de su corta vida. Mientras algunas cartas a la reina estaban dictadas por la mano del príncipe, otras - con una letra infantil y casi ilegible- dejaban traslucir más nítidamente el afecto

\footnotetext{
96 Kalnein 2001: 488.

97 Véase Egido 1973: 184.

98 BNE, ms. 18211, f. 56 v.

99 BNE, ms. 18211, f. 58.

100 Gómez-Centurión Jiménez 1983: 20.

101 Cortés Osorio 1984: 98.

102 BNE, ms. 18211, f. 69.
}

de aquel niño que se había visto privado del calor maternal: «No dudo de tu cariño, lo que celebras, es buena salud y me huelgo de ver por tus cartas tienes lo que yo te deseo". ${ }^{103}$ Finalmente, una prematura muerte preservó a don Juan de un seguro derrumbamiento político. ${ }^{104}$ Este falleció en soledad el 17 de septiembre de 1679, abandonado por su hermanastro y traicionado por todos los que le habían apoyado dos años antes. Mientras Carlos II se vanagloriaba de su próximo casamiento con la princesa María Luisa de Orleans, y la reina Mariana preparaba su triunfal regreso al lado del trono, el príncipe bastardo agonizaba solo. Incluso su funeral se vio privado de la pompa que caracterizaba los fallecimientos regios. De hecho, las órdenes de Carlos II se limitaron a que «se lleve su cuerpo difunto a ese convento [de El Escorial] para que se ejecute su entierro en él, con los oficios acostumbrados». ${ }^{105}$ Con su muerte, muchas de las reformas que aquel príncipe había proyectado finalmente se fueron con él.

Una vez desaparecida su incómoda sombra, Carlos II llamó a su lado a su madre. Tras dos años de destierro, Mariana de Austria retornaba a la Corte, gozando de una enorme ascendencia sobre su hijo, aunque sin volver a inmiscuirse oficialmente en el asfixiante ambiente de las conspiraciones palatinas. ${ }^{106} \mathrm{Y}$ ahora que su patrona volvía a ocupar un lugar preponderante cerca del rey, los tres predicadores jesuitas que permanecían en la Corte se desligaron completamente de sus forzados compromisos con don Juan. De hecho, a partir de ese momento empezaron a escucharse sermones que criticaban la figura del valido y ensalzaban a doña Mariana. En uno de sus sermones predicado en 1679, el padre Rodríguez Coronel recuperó una vez más la figura de la Virgen para elogiar a la reina. ${ }^{107}$ Del mismo modo que María fue obligada a abandonar su patria por el tirano Herodes y vio cómo apresaban a su hijo y lo apartaban de su lado para juzgarlo, "es así Señora y Reina Nuestra, que los enemigos de vuestro hijo intentaron ultrajar su persona, que asestaron contra él los dardos y las saetas; pero como las arrojaba contra sus ventajas la violencia de la envidia, [...] hicieron más gloriosa su corona». ${ }^{108}$

Como cabía esperar, hubo represalias para los predicadores más afectos al príncipe. ${ }^{109}$ Fray Manuel de Guerra y Ribera se vio obligado a huir al exilio, recluyéndose brevemente en un convento de Lisboa hasta que las aguas se calmasen. ${ }^{110}$ Para contestar a las exacerbadas críticas del jesuita Cortés Osorio, el trinitario había ya escrito un panfleto titulado Visita de la Esperanza y el Tiempo, en el que justificaba punto por punto todos los logros y dificultades de su príncipe: «Para fundir esta nueva Monarquía, se necesitan moldes, materia y artífices; el molde tenemos en S.A, los artífices no se hallan; la materia no se encuentra». ${ }^{111}$ Aunque

103 AHN, Estado, legajo 2729, carta de Carlos II a doña Mariana de Austria, 8 de noviembre de 1677.

104 Maura 1990: 235.

105 AGP, Reinados Carlos II, Caja 143, ex. 1.

106 Lozano Navarro 2005: 347.

107 García Pérez 2019: 140.

108 Rodríguez Coronel 1694: 149.

109 Soria Ortega 1991: 64.

110 El padre Guerra y Ribera regresó a Madrid pocos meses después, coincidiendo con el ambiente festivo que generó el matrimonio de Carlos II, pero ni aun entonces se libró de responder por sus compromisos con el fallecido Juan José de Austria. Véase Herzig 2008.

111 Guerra y Ribera 1676: 36 v. 
el trinitario consiguió retornar a la Corte coincidiendo con el nuevo matrimonio del rey, jamás pudo librarse de sus años como panegirista de don Juan, hasta el punto de que toda su producción fue constantemente criticada por sus enemigos. ${ }^{112}$

Ese mismo año de 1679 murió también el patriarca de Indias, don Antonio Manrique de Guzmán, tras haber vivido los años más conflictivos de la regencia y el ministerio de don Juan. ${ }^{113}$ El nuevo patriarca, don Antonio de Benavides y Bazán, heredaba una Capilla Real sometida a la reforma de 1677 y condicionada por varias circunstancias a tener en cuenta. En primer lugar, la muerte de Juan José de Austria suponía, en muchos sentidos, el fin de su gran obra. Cuando el nuevo primer ministro, el duque de Medinaceli, se hizo cargo del gobierno, no echó por tierra las reformas del bienio anterior, pero nunca ejerció una presión tan apasionada como había hecho don Juan. ${ }^{114}$ En segundo lugar, las diferentes religiones vieron la muerte del príncipe como una nueva oportunidad. Ahora que su imponente sombra se había difuminado, los superiores de las órdenes consideraron que se abrían nuevas oportunidades para volver a llenar la Real Capilla de predicadores. Y, finalmente, estaba el asunto de si se habían conseguido o no los resultados esperados. ¿Realmente se había reducido el gasto en la capilla palatina? ¿Había servido de algo la expulsión indiscriminada de tantos predicadores? Era algo que, en muchos sentidos, no estaba nada claro.

Si el patriarca de Indias tenía algo por seguro era que debía aprovechar las reformas implantadas por don Juan. ${ }^{115}$ La idea era fijar un mayor control del gasto, limitar el acceso de aspirantes y mantener, dentro de unos límites respetables, todo el boato y la gloria ceremonial que había marcado el barroco siglo XVII. ${ }^{116}$ En lo que a la plantilla de predicadores se refiere, las reglas habían cambiado completamente con respecto a los inicios del reinado de Carlos II. De hecho, se mantuvo intacta la norma del número de tres predicadores, por lo que la competencia y rivalidad para obtener una plaza, ya muy elevadas durante la regencia, eran ahora feroces. ${ }^{117}$ Los generales y provinciales de las órdenes estaban más que atentos a cualquier vacante dentro de las tres plazas de su religión para proponer a sus respectivos candidatos. Por ejemplo, en 1681, el procurador general de los dominicos presentó a fray Bernardo Cano, «en consideración de hallarse su religión con solos dos sujetos que gocen de esta honra, y por concurrir en este religioso las prendas que se requieren para el empleo". ${ }^{118}$ Asimismo, cuando el vicario general de los agustinos recoletos quiso presentar a fray José de Jesús María, enfatizó la circunstancia de que

112 García Pérez 2017: 258.

113 AGP, Registro, libro 6151, f. 79.

114 Kamen 1981: 586.

115 Sobre don Antonio de Benavides y Bazán, patriarca de Indias y capellán mayor entre 1679 y 1691, no existe todavía un estudio biográfico en profundidad. Incluso podría decirse algo similar de la figura de patriarca de Indias en general. Sobre sus funciones durante el reinado de Carlos II véase Álvarez-Ossorio Alvariño 2002: 314.

116 Sobre la utilización de la oratoria sagrada en la Real Capilla como mecanismo de legitimación y fortalecimiento de la dinastía de los Habsburgo véase Negredo del Cerro 2002.

117 García Pérez 2015: 685.

118 AGP, Personal, Caja 7742, ex.5. Expediente de fray Bernardo Cano. «en toda esta dicha Congregación no se halla más de con un predicador de V.M y haber tenido algunos más en tiempo del Sr. D. Felipe Cuarto que está en el cielo». ${ }^{119}$

Esta nueva situación hizo evidente el hecho de que ahora los generales y provinciales tenían mayores oportunidades de privilegiar a sus favoritos. Durante el período de la regencia, los grandes honores y prerrogativas que habían acumulado los predicadores reales habían comenzado a molestar a sus superiores. Teniendo presente el importante papel que los predicadores jugaban en las reuniones capitulares, y que gozaban además de lujos prohibidos para el resto de sus hermanos en los conventos que debían acogerles, podrá imaginarse que las críticas hacia esta élite palaciega habían sido enormes. ${ }^{120}$ Mientras algunos se habían prestado a no disfrutar de dichas prerrogativas, como fray Francisco de Jerez, pues «en los capuchinos [...] no gozan los [predicadores] de V.M. preeminencia alguna por ser iguales en todo", ${ }^{121}$ otros tenían un nivel de vida muy envidiable. De hecho, las quejas por parte de los superiores de los conventos de Madrid que los mantenían, habían crecido imparables durante aquellos años. Así que, tras la reforma, generales y provinciales volvían a tener en su mano la llave para introducir en la Corte a sus favoritos.

Pero, contra todo pronóstico, durante los años inmediatamente posteriores a la muerte de don Juan, empezaron a llegar a Palacio memoriales de eclesiásticos que presentaban su candidatura por su cuenta y riesgo, sin contar con ningún patrocinio, y exponiendo sus méritos como única carta de garantía para impresionar al patriarca de Indias. La plaza de predicador era una recompensa tan suculenta y las posibilidades de promoción tan limitadas, que valía la pena arriesgarse. Esta tendencia no solo fue una constante durante el resto del siglo XVII, sino que, con cada año que pasaba, hubo más religiosos que se atrevían a patrocinarse de forma independiente. De hecho, en los últimos momentos del reinado de Carlos II, la mayoría de candidatos ya no necesitaban de una carta de presentación para poder optar a una plaza, lo cual no quiere decir que no siguiesen ejerciendo influencia dichos documentos. Hasta tal punto era así que, veinte años después de la reforma, es decir en 1699, prácticamente todos los predicadores que se incorporaron a la plantilla no contaban ya con una carta de sus superiores. ${ }^{122}$

Si algo demostró que la reforma de 1677 tenía grietas preocupantes, fue el hecho de que muchos de los predicadores que habían sido expulsados estaban haciendo lo imposible para volver a la Corte. Mientras la plantilla se llenaba de nuevas voces, oradores veteranos enviaban también memoriales para poder regresar. Los siguientes veinte años, el patriarca de Indias tuvo que lidiar con esta doble realidad: el ingreso de nuevos predicadores y el retorno de algunos de los expulsados. Y entre estos segundos, muchos estaban arropados por personajes importantes, al igual que cuando, años atrás, habían suplicado su ingreso en la Real Capilla. Por ejemplo, en 1684, el duque de Montalvo pidió a Carlos II que

119 AGP, Personal, Caja 7742, ex. 9. Expediente de fray José de Jesús María.

120 AGP, Real Capilla, Caja 218, ex. 2.

121 AGP, Personal, Caja 7738, ex. 2. Expediente de fray Francisco de Jerez.

122 Véase AGP, Registro, libro 6151, f. 97. 
reintegrase al jesuita Juan de Ribera - expulsado por orden de don Juan-, quien por aquel entonces era su confesor. ${ }^{123}$ Asimismo, el jerónimo Justo de Salabert solicitaba ser reintegrado "respecto de que dicha merced no se le hizo a la religión sino a la ciudad y Reino [de Aragón]», ${ }^{124} \mathrm{Y}$ otro ejemplo lo ofrece Juan de Sandoval, de los clérigos menores, que estaba arropado por su padre, el conde de Ventosa. ${ }^{125}$

Este grupo de predicadores se valió de todas sus armas para obtener nuevamente una merced que, en esencia, ya había sido suya. Unas veces, hacían hincapié en los años de antigüedad de su título de predicadores. Cuando el mercedario Miguel Mayers solicitó ser restituido, alegó que había sido expulsado «por ser entonces el más moderno de su religión, y por cuanto hoy se halla el más antiguo de todos» ${ }^{126}$ merecía volver. Otras veces, justificaban los escasos inconvenientes que tenía para la Corona el ser reincorporados. Por ejemplo, fray Tomás de Argüello argumentaba los pocos privilegios de los que gozaba la orden de bernardos, pues «los predicadores de S.M. por tales predicadores no tienen voto en los capítulos generales, ni extraordinario alguno, ni compañeros». ${ }^{127}$ Igualmente, fray Pablo Casteli se escudaba en que vivía permanente en Milán, y, por lo tanto, no suponía ningún gasto para la ya elevada plantilla de predicadores que residían en la Corte. ${ }^{128} \mathrm{Y}$ de igual modo actuó el jesuita Agustín de Herrera sobre que «no se le hace perjuicio a su Religión porque en ella no se goza de las preeminencias que en otras». ${ }^{129}$ Otras veces recalcaban sus logros mientras sirvieron al rey, como escribía el agustino fray Juan de Ortega que "siempre que se le ha mandado predicar en la Real Capilla ha obedecido con mucho gusto»..$^{130}$

Sin lugar a duda, aquella situación era realmente extraordinaria dentro de la Real Capilla. Durante el reinado de Felipe IV se había constatado un crecimiento progresivo de los nombramientos de predicadores, que aumentó hasta límites insospechados bajo la regencia de Mariana de Austria. ${ }^{131}$ Pero a partir de 1680 se vivió una doble realidad antaño desconocida: por un lado, el número de nuevos aspirantes empezó a aumentar conforme pasaban los años. Entre 1680 y 1685 hubo alrededor de 34 nombramientos, y el lustro siguiente aumentó a $76 .{ }^{132}$ Pero, como se viene diciendo, a esta vía de acceso había que sumarle otra, y era la reintegración de los predicadores veteranos.

Si algo puede afirmarse también es que la reforma de 1677 quedó, en última instancia, sometida a los intereses de las distintas facciones y a las presiones que las órdenes

123 AGP, Personal, Caja 7738, ex. 10. Expediente de Juan de Ribera.

124 AGP, Personal, Caja 7736, ex. 9. Expediente de fray Justo de Salabert.

125 AGP, Personal, Caja 7740, ex. 9. Expediente de Juan de Sandoval.

126 AGP, Personal, Caja 7740, ex. 4. Expediente de fray Miguel Mayers.

127 AGP, Personal, Caja 7736, ex. 6. Expediente de fray Tomás de Argüello.

128 AGP, Personal, Caja 7953, ex. 9. Expediente de fray Pablo Casteli.

129 AGP, Personal, Caja 7741, ex. 9. Expediente de Agustín de Herrera.

130 AGP, Personal, Caja 7737, ex. 12. Expediente de fray Juan de Ortega.

131 El nombramiento de predicadores durante el periodo de la regencia fue constante en lo elevado del número de nuevos aspirantes. Solo entre 1670 y 1675 ingresaron 103: 1670 (15), 1671 (13), 1672 (24), 1673 (17), 1674 (14), 1675 (20). Véase García Pérez 2015: 681.

132 AGP, Registro, libro 6151, ff. 78-83 v. religiosas volvían a ejercer en Palacio. La sombra del príncipe había sido demasiado opresiva, hasta el punto de que las demandas de nuevas incorporaciones se habían detenido completamente. Pero el duque de Medinaceli y el conde de Oropesa ya no representaban lo mismo que don Juan. El caudillismo de este había dado paso a otro tipo de gobierno mucho más condicionado por las exigencias de la aristocracia, las intrigas políticas y, no está de más añadir, las presiones de las consortes del rey. ${ }^{133}$ De modo que ambos primeros ministros jamás contaron con la fortaleza suficiente como para apuntalar el programa reformista del bienio anterior. Como muchas otras de las reformas programadas por don Juan, aquella ambiciosa medida finalmente terminó inconclusa. ${ }^{134}$

Sin embargo, no todo fue negativo. Aunque gran parte de los cambios empezaron a derrumbarse en los años inmediatamente posteriores a la muerte de don Juan, hubo ciertas modificaciones que acercaban aquella Real Capilla a la que sería bajo los Borbones. El hecho de que el número de predicadores reales se limitase - aunque con excepciones- a tres, truncó el predominio de las órdenes religiosas con mayor influencia. ${ }^{135}$ Durante la regencia de Mariana de Austria, los franciscanos, dominicos, jesuitas y agustinos habían gozado de una situación privilegiada dentro de la Real Capilla. ${ }^{136}$ Sin embargo, a partir de 1680 se constata un mayor equilibrio entre todas las órdenes, debido a que cada una de ellas únicamente podía mantener a tres miembros. No es casualidad, por tanto, que los hijos de San Bernardo, los jerónimos o los premostratenses consiguiesen gozar de mayores oportunidades de predicar en el púlpito regio. Pero además pudieron ingresar algunas que jamás habían tenido opciones reales de acceso. De hecho, el patriarca justificó la dejadez o reiteradas ausencias que mostraban algunos oradores de Palacio para traer nuevas voces. Es el caso de los hijos de San Camilo. La Orden de Clérigos Regulares Ministros de los Enfermos nunca había tenido representación en la capilla palatina. Pero en 1686 don Antonio Benavides escribió a Carlos II presentando a fray Domingo Gange para que lo nombrase "por uno de sus predicadores con que V.M. alentará el celo con que este sujeto se dedica continuamente al bien público. Y quedará honrada su religión». ${ }^{137}$

Durante los años noventa del siglo XVII, la situación en la Real Capilla continuó arrastrando los problemas de épocas pasadas. Si había quedado algún atisbo de la reforma de 1677 , este se reducía principalmente a la regla de tres predicadores por religión, lo cual siempre incluía excepciones. Las dificultades económicas que atravesaba la Monarquía, las guerras con Francia y los frustrados intentos del patriarca de Indias por sostener un boato ceremonial demasiado costoso, obligaron al rey a solicitar, una vez más, que se redujese el gasto de la Real Capilla. ${ }^{138}$ La concesión de gajes a los criados estaba pasando, de hecho, por días muy complicados y muchos de los predicadores veteranos tenían problemas para cobrar los gajes pendientes. Eso mismo le ocurrió

\footnotetext{
133 Lynch 1992: 331.

134 Kalnein 2001: 498.

135 García Pérez 2015: 688.

136 Negredo del Cerro 2006: 54.

AGP, Personal, Caja 7749, ex. 8. Expediente de fray Domingo
} Gange.

138 Sánchez Belén 2001: 419. 
a fray Luis de Tineo, de los premostratenses, que escribió durante años al rey informándole de que «V.M. con su real piedad fue servido de hacerle merced de los gajes de su predicador para que pudiese sustentarse decentemente, [...] y por cuanto no los cobra, y se le estarán debiendo cerca de ocho mil reales». ${ }^{139}$

Hasta tal punto era así, que la obtención de dicho salario se había convertido en un verdadero privilegio casi inalcanzable para la mayoría. De hecho, muchos de los predicadores que suplicaban gajes cuando quedaba una vacante, tardaban largos años en conseguirlos, si es que finalmente era así. Por ejemplo, uno de los predicadores más famosos de las postrimerías del reinado de Carlos II, fray Francisco de Santa Clara, escribió directamente a la reina madre, consciente de las enormes dificultades que suponía conseguir aquellos gajes. ${ }^{140}$ Suplicándole que "le favorezca con su real patrocinio para que en la primera ocasión le señale el Rey N. S. gajes de predicador por tener una madre pobre $"{ }^{141}$ Santa Clara esperaba finalmente conseguirlo. Pero ni siquiera su fama le ayudó, pues tuvo que esperar siete años más para obtenerlos.

Además, se daba otro gran problema que Juan José de Austria había intentado subsanar mediante aquella drástica reforma de predicadores: el absentismo de los criados de la Real Capilla. Uno de los fines de la reforma de 1677 había sido, precisamente, que los pocos predicadores integrados en la lista residiesen de forma permanente en Madrid para ocuparse de sus oficios. Pero cuando el príncipe murió, y el número de predicadores volvió a aumentar, regresó la veterana costumbre de que muchos de estos predicadores se ausentaran de Palacio, llevándose con ellos su título como un auténtico trofeo. $Y$ aunque debían justificar al patriarca los motivos de su salida de la Corte, siempre sabían encontrar alguna misión encargada por sus superiores. ${ }^{142}$

Para cuando Carlos II murió en 1700, muchos predicadores esperaban todavía cobrar sus mensualidades pendientes, el absentismo del personal de la Capilla era la tónica habitual y las grandes festividades programadas por la Corona precisaban un capital del que no se disponía. ${ }^{143}$ De modo que, en última instancia, la reforma de predicadores de 1677 fue uno más de los intentos de cambio, si bien es cierto que, por un momento, pareció que era posible conseguirlo.

\section{CONCLUSIONES}

La reforma de predicadores de 1677 fue una medida que cambió algunas pautas de la Real Capilla de los Austrias. Cuando el príncipe don Juan se decidió a actuar, la capilla palatina arrastraba una situación realmente complicada, y esto por varios motivos. En primer lugar, el número de predicadores nombrados había aumentado desorbitadamente

\footnotetext{
139 AGP, Personal, Caja 7729, ex. 4. Expediente de fray Luis de Tineo.

140 Álvarez-Ossorio Alvariño 2004: 119.

141 AGP, Personal, Caja 7746, ex. 8.Expediente de fray Francisco de Santa Clara.

142 En 1688, el patriarca informaba a Carlos II que de los ocho predicadores de San Benito que contaba la Real Capilla, tres no se hallaban en Madrid y otro no había tomado posesión. AGP, Personal, Caja 7952, ex. 10. Expediente de Plácido Huergo Valdés.

143 Habría que esperar al reinado de Felipe $V$ para que se implantasen nuevas reformas en la Real Capilla. Sin embargo, gran parte de ellas se plasmarían recuperando las modificaciones introducidas por don Juan. Véase Saavedra Zapater 2005.
}

desde los inicios del siglo XVII. De hecho, las Constituciones de 1623 no habían contemplado los niveles de crecimiento de oradores de Palacio, hasta el punto de que durante el ministerio de Fernando de Valenzuela se incorporó más de la mitad de los predicadores que habían poblado el reinado de Felipe IV. Otro problema que se estaba viviendo en la Real Capilla eran las grandes tensiones que se respiraban en el púlpito. Durante décadas, los predicadores habían constituido elementos a tener en cuenta. Esto se debía, en esencia, a que esta élite palaciega gozaba de un momento estelar mientras predicaba el sermón, ya que nadie podía impedir que dirigiese sus elogios o críticas a la Corte. El rey, y por extensión su valido, se hallaban expectantes ante el predicador. Ello provocó una progresiva instrumentalización de la oratoria sagrada. Si el conde duque de Olivares había sabido maniobrar para conseguir tal objetivo, durante la regencia de Mariana de Austria se constató una peligrosa implicación de los predicadores reales en las disputas políticas. Las tensiones surgidas a raíz de los enfrentamientos entre la regente y Juan José de Austria fueron también contestadas desde la Capilla Real. Los años inmediatamente anteriores a la subida al poder del príncipe bastardo, el púlpito sirvió de plataforma para lanzar feroces críticas hacia uno de los dos bandos. En muchos sentidos, este grupo de predicadores había abandonado su primitiva misión pastoral para utilizar los sermones como arma política, la mayoría de las veces disfrazando sus argumentos con referencias bíblicas.

Esta doble situación -el exceso de predicadores en plantilla y la implicación de estos en la lucha política- motivó la reforma de predicadores de 1677 . Ciertamente, don Juan planificó un programa reformista que se extendía a otros muchos ámbitos de la Monarquía. La Real Capilla fue solo una pieza más del gigantesco puzle. De hecho, cuando se decidió lo que iba a suponer la expulsión indiscriminada de un gran número de predicadores, se justificó con unos claros fines económicos, que se basaban principalmente en la disminución del elevado gasto de la Real Capilla y un mayor control sobre los nombramientos. Sin embargo, reducir las causas de tamaña reforma a esa razón sería limitar en exceso las motivaciones del príncipe, porque también hubo pretextos de carácter político.

Primeramente, Juan José de Austria heredaba una situación de continua vigilancia y persecución de los predicadores del rey. Fernando de Valenzuela ya había actuado en ese sentido mediante destierros y premios. El príncipe asumió aquella purga invirtiéndola y recompensando a sus fieles aliados en el púlpito. El mismo hecho de que los jesuitas fuesen temporalmente expulsados de palacio - aun cuando tres de ellos habían sido incluidos en la lista de predicadores-, pone también de manifiesto que el príncipe estaba limpiando el Real Alcázar de cualquier afecto a la reina madre. Además, esta purga de predicadores era otro mecanismo más destinado a instrumentalizar la oratoria sagrada. En la lista que confeccionó el patriarca de Indias estaban incluidos los predicadores que tan ardorosamente habían defendido la causa de Juan José de Austria. Sus riesgos a la hora de exaltar en el púlpito las virtudes del que ahora era primer ministro y baluarte del joven rey, les había valido una gran recompensa. De modo que, finalmente, las motivaciones políticas primaron en muchos sentidos sobre los intereses económicos. 
Una de las cuestiones más importantes es dilucidar si la reforma de predicadores realmente consiguió sus objetivos. Es difícil saberlo, sobre todo si tenemos en cuenta que el príncipe don Juan murió tan solo dos años después de ponerla en marcha. Pero lo cierto es que, ya en sus inicios, adolecía de problemas importantes. Primeramente, la Junta que compartían el patriarca de Indias y el mayordomo mayor pronto se convirtió en un nido de disputas por controlar las decisivas reformas que se estaban llevando a cabo. Si tenemos además presente que en 1679 Carlos II volvía a solicitar que se frenase la distribución de gajes, puede suponerse que, a corto plazo, la Real Capilla todavía arrastraba gastos importantes. Poco importó, porque una vez que murió Juan José de Austria, la reforma presentó grietas evidentes que se relacionaban con la difícil situación política y económica que marcó la década de los ochenta del siglo XVII.

El duque de Medinaceli asumió las reformas del bienio anterior, pero jamás actuó tan ardorosamente. El nuevo patriarca de Indias, don Antonio de Benavides, intentó continuar con el programa reformista puesto en marcha por su antecesor, pero muy pronto se constataron los contratiempos. Las órdenes religiosas volvían a presionar para introducir nuevos miembros, los antiguos predicadores expulsados insistían mediante reiterados memoriales para que se les dejase regresar, la economía castellana se hundía progresivamente y la Real Capilla no podía limitar el gasto sin desvirtuar toda la pompa y fastuosidad que caracterizaba el ceremonial de los Austrias.

Es cierto también que la reforma de predicadores no se desvaneció del todo tras la muerte de don Juan. Un primer signo de esto es que el número de tres predicadores continuó intacto. Las órdenes se vieron obligadas a jugar unas nuevas reglas y debían esperar, por lo general, a que un predicador muriera o fuese demasiado mayor para volver a proponer un candidato. Asimismo, la concesión de gajes se convirtió en un auténtico privilegio del que muy pocos gozaban, y por el que los predicadores más veteranos batallaban sin descanso. Y además, órdenes con una influencia mucho más marginal como eran los monjes camilos, consiguieron por primera vez introducir predicadores en la Real Capilla.

En esencia, la década de los ochenta experimentó un mar de contradicciones dentro de la Real Capilla. Si bien se intentó controlar la entrada de nuevos miembros, el número de nombramientos volvió a aumentar. En gran medida, los intereses y los compromisos de la Corona pesaron más. De tal modo que, cuando finalmente irrumpió en la Corte la reina Mariana de Neoburgo en 1690, la situación Ilegó a límites preocupantes. Hubo que esperar, ciertamente, al siglo XVIII para poder constatar nuevos programas de cambio, aunque, en muchos sentidos, la reforma de predicadores que estableció Juan José de Austria se convirtió en un precedente que no debió pasarse por alto.

\section{FUENTES}

Cortés Osorio, Juan. 1984. Invectiva política contra don Juan de Austria. Madrid: Editora Nacional.

Guerra y Ribera, Manuel de. 1676. Visita de la Esperanza y el Tiempo. Madrid.

Guerra y Ribera, Manuel de. 1677. Sermones varios de santos dedicados al serenísimo señor D. Juan de Austria. Madrid: imp. Juan Paredes.
Ludeña, Juan. 1675. Sermón de los siete dolores de María Santísima Nuestra Señora en el viernes del Concilio. Madrid: Antonio Francisco de Zafra.

Rodríguez Coronel, Juan. 1675. Sermón a las honras que por orden de S.M. la Reina nuestra señora se celebraron en el Hospital Real del Buen Suceso a los que perecieron en el incendio de la Plaza Mayor de esta Corte. Madrid: José Fernández Buendía.

Rodríguez Coronel, Juan. 1694. Sermones Exhortatorios y de Cuaresma. Primera parte. Madrid: Juan García Infanzón.

Rodríguez Coronel, Juan. 1695. Sermones Exhortatorios y de Cuaresma. Segunda parte. Madrid: Juan García Infanzón.

Rubio, Francisco. 1677. Threno sacro, oración fúnebre panegírica, en las honras y piadosos manes del potentísimo rey de las Españas y monarca de ambos mundos, el señor Phelipe Quarto el Grande, el Católico, el Piadoso que reina ya en el Cielo. Madrid.

\section{BibLIOgRAFÍA}

Álvarez-Ossorio Alvariño, Antonio. 2002. «La sacralización de la dinastía en el púlpito de la Capilla Real en tiempos de Carlos I|». Criticón 84-85: 313-322.

Álvarez-Ossorio Alvariño, Antonio. 2004. «Facciones cortesanas y arte del buen gobierno en los sermones predicados en la Capilla Real en tiempos de Carlos II». Criticón 90: 99-123.

Álvarez-Ossorio Alvariño, Antonio. 2015. «Precedencia ceremonial y dirección del gobierno. El ascenso ministerial de Fernando de Valenzuela en la corte de Carlos II». En Vísperas de Sucesión: Europa y la Monarquía de Carlos II, editado por Bernardo José García García y Antonio Álvarez-Ossorio Alvariño, 21-55. Madrid: Fundación Carlos de Amberes.

Azanza López, José Javier. 2013. «Imágenes emblemáticas del adoctrinamiento regio: los sermones del predicador real José de Barcia en la Corte de Carlos II». Potestas 6: 255-297. https://doi. org/10.6035/potestas.2013.6.11

Burrieza Sánchez, Javier. 2008. «La Compañía de Jesús y la defensa de la Monarquía Hispánica». Hispania Sacra 121: 181-229. https:// doi.org/10.3989/hs.2008.v60.i121.54

Carrasco Martínez, Adolfo. 1999. «Los grandes, el poder y la cultura política de la nobleza en el reinado de Carlos II». Studia Historica. Historia Moderna 20: 77-136.

Castilla Soto, Josefina. 1990. "El "valimiento" de don Juan José de Austria (1677-1679)». Espacio, Tiempo y Forma. Historia Moderna 3: 197-211.

Cerdán, Francis. 1983. «El predicador y el poder. Estudio de un sermón cortesano: A la dedicación del templo de Lerma por Fr. Hortensio Paravicino». Areas 3-4: 221-229.

Cerdán, Francis. 2000. «Oratoria sagrada y homilía en el Siglo de Oro: el caso de la homilía». Criticón 79: 87-115.

Egido, Teófanes. 1973. Sátiras políticas de la España Moderna. Madrid: Alianza.

Garau Amengual, Jaume. 2006. «Notas para una biografía del predicador real Jerónimo de Florencia (1565-1633)». Revista de Literatura LXVIII, 135: 101-122. https://doi.org/10.3989/revliteratura.2006. v68.i135.4

García Pérez, Francisco José. 2015. «Los predicadores reales de Carlos II». Archivo Ibero-Americano 281: 673-711.

García Pérez, Francisco José. 2017. «La oratoria sagrada como arma política. Los predicadores reales de Juan José de Austria». Obradoiro de Historia Moderna 26: 237-265.

García Pérez, Francisco José. 2019. Juan Rodríguez Coronel: un predicador jesuita en la Corte de Carlos II. Madrid - Oporto: Sindéresis.

Gentilli, Luciana. 2012. «Cómo el predicador ha de reprender en el púlpito los pecados públicos de los Reyes». Imposibilia 3: 54-66.

Gómez-Centurión Jiménez, Carlos. 1983. «La sátira política durante el reinado de Carlos Il». Cuadernos de Historia Moderna y Contemporánea 4: 12-33.

Herzig, Carine. 2008. «La polémica en torno a la Aprobación del Padre Fray Manuel de Guerra y Ribera (1682-1684) y la moralización de la Comedia». Criticón 103-104: 81-92. 
Hermosa Espeso, Cristina. 2014. «El testamento de Felipe IV y la Junta de gobierno de la minoridad de Carlos II. Apuntes para su interpretación». Erasmo: Revista de Historia Bajomedieval y Moderna 1: $102-120$.

Herrero Salgado, Félix. 2006. La oratoria sagrada en los siglos XVI y XVII, Tomo V. Madrid: Fundación Universitaria Española.

Hortal Muñoz, José Eloy. 2015. «Los capellanes de los Sitios Reales durante el reinado de Felipe IV». Libros de Corte 3: 88-100.

Kalnein, Albrecht. 2001. Juan José de Austria en la España de Carlos II. Historia de una Regencia. Lleida: Milenio.

Kamen, Henry. 1981. La España de Carlos II. Barcelona: Crítica.

López-Cordón, María Victoria. 1998. «Mujer, poder y apariencia o las vicisitudes de una regencia». Studia Historica. Historia Moderna 19: 49-66.

Lozano Navarro, Julián José. 2005. La Compañía de Jesús y el poder en la España de los Austrias. Madrid: Cátedra.

Lynch, John. 1992. Los Austrias (1598-1700), Vol II. Barcelona: Crítica.

Martínez Gil, Fernando. 2011. "Los sermones como cauce de propaganda política: la Guerra de Sucesión». Obradoiro de Historia Moderna 20: 303-336. https://doi.org/10.15304/ohm.20.16

Maura, Gabriel. 1990. Vida y reinado de Carlos II. Madrid: Aguilar.
Negredo del Cerro, Fernando. 2002. «La palabra de Dios al servicio del Rey: la legitimación de la Casa de Austria en los sermones del siglo XVII». Criticón 84-85: 295-311.

Negredo del Cerro, Fernando. 2006. Los predicadores de Felipe IV. Corte, intrigas y religión en la España del Siglo de Oro. Madrid: Actas.

Negredo del Cerro, Fernando. 2012. "Los predicadores reales y el Conde Duque de Olivares». Libros de Corte 5: 112-117.

Sánchez Belén, Juan Antonio. 1996. La política fiscal en Castilla durante el reinado de Carlos II. Madrid: Siglo XXI.

Sánchez Belén, Juan Antonio. 2001. «La Capilla Real de Palacio a finales del siglo XVII». En La Capilla Real de los Austrias. Música y ritual de corte en la Europa moderna, editado por Juan José Carreras Ares y Bernardo José García García, 411-448. Madrid: Fundación Carlos de Amberes.

Sánchez Belén, Juan Antonio. 2014. «Eclesiásticos criollos en la Capilla Real de Palacio: una élite de poder en el reinado de Carlos Il». Revista de Indias 261: 423-452. https://doi.org/10.3989/ revindias.2014.014

Saavedra Zapater, Juan Carlos. 2005. El primer reformismo borbónico en Palacio: la Capilla Real (1700-1750). Madrid: Editorial UNED.

Soria Ortega, Andrés. 1991. El Maestro Fray Manuel de Guerra y Ribera y la oratoria de su tiempo. Granada: Universidad de Granada. 